\title{
Influence of Cyclic Impact Loading and Axial Stress on Dynamic Mechanical Properties of Burst-Prone Coal
}

\author{
Shuang Gong $\mathbb{D}^{1,2,3}$ Zhen Wang, ${ }^{1,2,3}$ Lei Zhou, ${ }^{1,2,3}$ and Wen Wang ${ }^{1,3}$ \\ ${ }^{1}$ School of Energy Science and Engineering, Henan Polytechnic University, Jiaozuo 454000, China \\ ${ }^{2}$ Henan Key Laboratory for Green and Efficient Mining \& Comprehensive Utilization of Mineral Resources, \\ Jiaozuo 454000, China \\ ${ }^{3}$ Collaborative Innovation Center of Coal Work Safety, Jiaozuo 454000, Henan Province, China \\ Correspondence should be addressed to Shuang Gong; gongcumtb@126.com
}

Received 21 December 2020; Revised 29 December 2020; Accepted 4 January 2021; Published 13 January 2021

Academic Editor: Guangchao Zhang

Copyright ( $\odot 2021$ Shuang Gong et al. This is an open access article distributed under the Creative Commons Attribution License, which permits unrestricted use, distribution, and reproduction in any medium, provided the original work is properly cited.

\begin{abstract}
High in-situ stress and frequent dynamic disturbances caused by the mining process in deep coal mines can easily induce dynamic disasters such as coal burst. We conducted laboratory experiments to assess the effects of the axial stress loading and dynamic cyclic impact loading on the dynamic mechanical properties of burst-prone coals by using a modified split Hopkinson pressure bar (SHPB). Comparisons were made using two types of burst-prone and burst-resistant coal samples. The mineral components, organic macerals, and dynamic mechanical features of both burst-prone and burst-resistant coal samples were comparatively analyzed based on the obtained X-ray diffraction (XRD), optical microscope observations, and dynamic compressive stress-strain curves, respectively. The results of the microstructure analysis indicated a larger difference between the minimum and maximum reflectances of vitrinite for burst-prone coal. Compared to the burst-resistant coal samples, the burst-prone coals contained less corpocollinite and fusinite. While applying a high axial static load combined with cyclic impact load, the coal samples showed the characteristics of fatigue damage. The results also demonstrated that preaxial stress affected the burst resistance of coal samples. The greater the preaxial stress was, the less the coal samples could withstand the dynamic cyclic impact load. In comparison to the burst-resistant coal sample, the burst-prone coal sample showed a larger dynamic compressive strength and a lower deformation. They were also more positively capable of the propagation and activation of the coal burst. We believe that the results of the study are conducive to further understanding of the distribution of microcomponents of burst-prone coals. The results are also beneficial for realizing the dynamic mechanical characteristics of burst-prone coals under the impact of cyclic dynamic load.
\end{abstract}

\section{Introduction}

Coal is China's basic energy and fuel resource, accounting for $59.0 \%$ of total energy consumption in 2019. With the continuous increase of the depth and intensity of coal mining, coal burst has become one of the main disasters restricting the safe and efficient mining of coal mine. This problem seriously affects the economic development and social stability of China [1-4]. Coal burst is a dynamic phenomenon characterized by sudden, rapid, and violent destruction, produced by the instantaneous release of elastic deformation energy in the coal mass around the mine roadway or stope [5-8]. Such coal burst can result in extensive damage to mine equipment (Figure 1(a)) and even can lead to numerous injuries and fatalities. The first recorded coal burst occurred in England in 1738. For more than 200 years, the harm due to coal burst has almost spread in mining countries all over the world. The coal burst disaster in China's coal mines is extremely serious. Since the first coal burst occurred in the Fushun Shengli mine in 1993, there have been more than 5000 coal burst accidents, resulting in hundreds of casualties and roadway damage of more than 30 kilometers. In the past 100 years, many exploratory studies have been carried out to enhance the understanding of the mechanism of coal burst and to obtain better prevention and control measures. However, the proposed mechanisms are rarely successfully applied to the interpretation, prediction, and prevention of coal burst. Due 


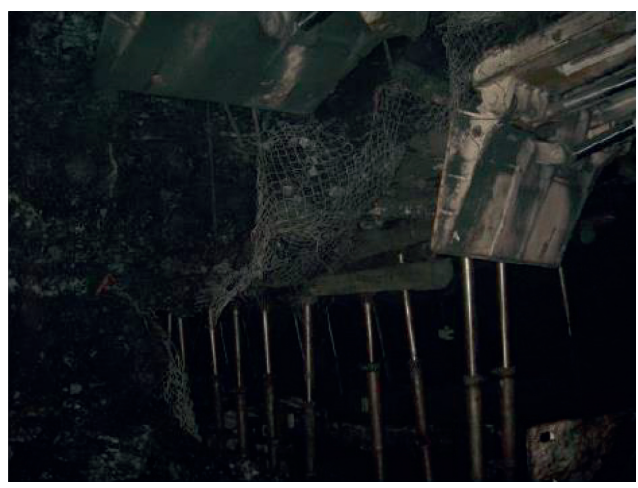

(a)

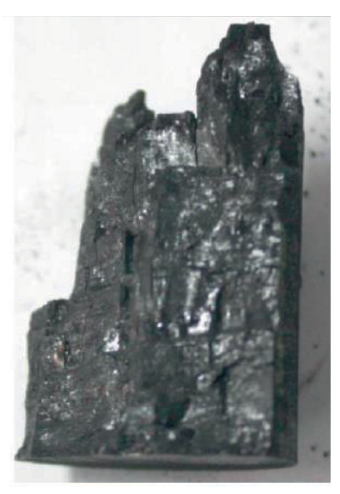

(b)

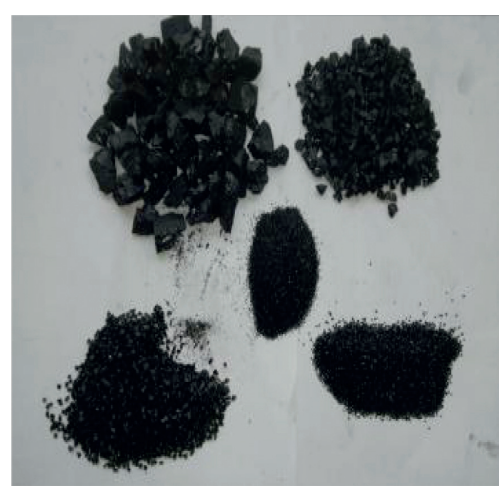

(c)

FIGURE 1: The fragmented coals: (a) ejected coal due to coal burst in front of the working face on site. (b) Quasistatic failure of the coal sample in the laboratory. (c) Dynamic failure of the coal samples in the laboratory.

to the destructive and instantaneous nature of such dynamic disasters, the coal bursts are unpredictable both in time and space. Many scholars have analyzed the process of coal burst as a dynamic stability problem. Based on the elastic, plastic, and stability theories, various theories such as stiffness theory, strength theory, energy theory, impact tendency theory, deformation system instability, and shear slip theory have been put forward successively [9]. Although these theories commonly relate the risk level of coal burst with the burst propensity of coal itself, the key characteristics of dynamic failure of coal under different stress paths, including cyclic impact disturbance and high axial stress, are still poorly understood and constrained.

There is a close relationship between the microdefects and the internal fine structure of coal mass with its physicalmechanical properties. Coal mass is a combination of minerals with various chemical compositions and crystalline lattices in different structural ways. The occurrence process of coal burst involves a slow accumulation and an instantaneous sudden release of strain energy in coal mass. From the perspective of coal composition structure, the energy accumulation and release characteristics of coal mass are largely determined by the macrostructural characteristics of coal mass, the microstructure of coal mass, and the distribution of various components. In the past, researchers analyzed the structure of coal, which is easy to experience outbursts, according to the structural physics technique, and found that the macromolecular structure forms a "spherical" shape [10]. Also, the analysis of the composition and structure of coal rocks with burst tendency indicated that the content of clastic particles in rocks had a positive correlation with the possibility of coal burst [11]. However, there is no report in the literature on the diversity of microstructure characteristics between resistant and prone coals.

With the fast development of the national economy, an increasing demand occurs in China for various resources. As the shallow resources are gradually being depleted, the exploitation of deep resources is the inevitable future direction of resource extraction. Under the condition of shallow mining, because the stress load of surrounding rock is mostly self-weight stress, some mines belong to noncoal burst mine. However, after entering the field of deep mining, the geological structure becomes complex, the self-weight stress increases, and a large quantity of solid energy is accumulated in the coal rock mass. Under the action of deep in-situ stress, tectonic stress, and engineering disturbance, the accumulated energy is greater than the energy required for the instability and failure of the ore body. This leads to the loss of structural stability of the whole coal rock mass system and the occurrence of coal burst. In the process of coal mining, the coal seam is often affected by cyclic impact loads, including geological structure movement, periodic roof fracture, and impact disturbance caused by blasting stress wave. The dynamic mechanical properties of coal mass under cyclic impact load are one of the important factors affecting coal mine safety production. Many scholars have performed a lot of research on the mechanical properties of coal under cyclic loading. The total absorbed energy, total consumed energy, and corresponding damage variable of rock specimen under different impact velocities have been studied $[12,13]$. The failure mode of sandstone under the combined action of cyclic impact and static loads, the damage variable, and dynamic mechanical characteristics have been investigated by the SHPB device [14, 15]. The deformation and strength characteristics, energy transfer law, and failure mode of rock under the combination of dynamic/fast and static/slow loadings have been widely investigated. The theoretical model of rock dynamic fracture and the constitutive model corresponding to static and dynamic combined loading have been already put forward $[16,17]$. Until now, the dynamic mechanical property tests of rock and common coal materials have been broadly examined. However, only a few research attempts have been conducted on the burst-prone coal (Figure 1), especially on its microstructure characteristics, and the influence of axial pressure and cyclic impact on its dynamic mechanical properties.

In this work, the effects of mineral contents and organic macerals on the burst propensity of coal were scrutinized through XRD and optical microscope. Based on the microscopic experiment, the clay mineral and amorphous content of coal with a different burst propensity were 
compared. The microstructural parameters of coal, such as maceral content, distribution characteristics, and vitrinite reflectance, were observed and analyzed. Moreover, experiments were conducted on both burst-prone and burst-resistant/neutral coals under different preaxial stresses and cyclic impact loads using the SHPB system. The stress-strain curve characteristics of coal with a different burst propensity were compared and discussed. Besides, the influence of the preaxial stress and cyclic impact on dynamic mechanical features of coal was investigated. These experimental observations serve as the scientific foundations for the responsible mechanisms that trigger and evolve coal burst.

\section{Experimental Setup}

2.1. Sample Preparation. We gathered large pieces of fresh coal from the No. 2 coal seam of Qianqiu coal mine in Sanmenxia City, located in Henan Province of China. Considering the large-scale coal burst accident which occurred in the mining process of No. 2 coal seam in Qianqiu mine on November 3,2014, the coal of this mine is generally recognized as the coal with a strong burst-prone tendency. The depth of the coal seam is $-1060 \mathrm{~m}$. Based on the in-situ stress test results, the maximum horizontal stress is 18.76 MPa, the minimum horizontal stress is $12.01 \mathrm{MPa}$, and the vertical stress is $17.86 \mathrm{MPa}$. Industrial analysis of coal petrology shows that the moisture content of Qianqiu coal is $2.92 \%$, the ash content is $25.34 \%$, the volatile matter is $7.59 \%$, and the fixed carbon content is $64.15 \%$. Based on the determination of the porosity by mercury injection, the porosity of coal is $27 \%$.

For the sake of comparison, we also gathered fresh coal blocks from the No. 7 coal seam of Zhaogezhuang coal mine in Tangshan City, located in Hebei Province of China. No coal burst accident has occurred in the mining history of this coal seam. The coal is generally considered to be resistant to coal burst and its depth is $-1100 \mathrm{~m}$. According to the in-situ stress test results, the maximum horizontal stress is 17.55 $\mathrm{MPa}$, the minimum horizontal stress is $9.12 \mathrm{MPa}$, and the vertical stress is $21.12 \mathrm{MPa}$. Also, the moisture content of Zhaogezhuang coal is $2.90 \%$, the volatile matter is $26.16 \%$, the fixed carbon content is $68.28 \%$, and the ash content is $2.66 \%$. Based on the porosity measurement under mercury injection, the porosity of Zhaogezhuang coal is $34 \%$.

After the coal was cut and collected, it was wrapped immediately to avoid drying and oxidation during transportation. Based on the method recommended by ISRM, the coal samples were drilled from coal blocks as cylinder samples with a diameter and height of $50 \mathrm{~mm}$. The flatness and parallelism of the two ends of the sample should be $\pm 0.05 \mathrm{~mm}$ and $\pm 0.02 \mathrm{~mm}$, respectively. The experimental coal samples and their geometric dimensions are shown in Figure 2. Before the dynamic cyclic impact test, the physical and mechanical properties of coal samples were tested, as shown in Table 1. The abovementioned results demonstrated the lower quasistatic compressive strength of Zhaogezhuang coal compared to Qianqiu coal. However, the porosity of Zhaogezhuang coal was larger than that of Qianqiu coal.
2.2. Split Hopkinson Pressure Bar (SHPB) Apparatus and Its Basic Principles. This study aimed to analyze the dynamic mechanical properties of burst-prone coal under the combined action of the high static load and cyclic impact load. To simulate the complex mechanical environment of high ground stress and frequent dynamic disturbance of deep coal rock, the improved triaxial SHPB dynamic loading device was chosen to apply the confining pressure and axial pressure. The improved triaxial SHPB system is predominantly composed of the gas gun, spindle punch, incident bar, transmitting bar, confining pressure system, strain gauge, axial compression system, data acquisition, and display equipment (Figures 3(a) and 3(b)). The spindle punch, incident bar, and transmitting bar are constructed from $40 \mathrm{Cr}$ alloy steel with high strength. Its longitudinal wave velocity is $5447 \mathrm{~m} / \mathrm{s}$, uniaxial compressive strength is $800 \mathrm{MPa}$, and elastic modulus is $240 \mathrm{GPa}$. The loading wave is a half-sine wave stress pulse loaded with a constant strain rate. CS-1D ultradynamic strain gauge and DL-750 oscilloscope were employed to collect the test data.

To record reflected strain and incident waves, the strain gauge on the incident bar was utilized, and the strain gauge on the transmitting bar was also used to record the transmitted strain wave. Based on the stress wave theory, the dynamic stress, strain rate, and strain formulas of the specimen are obtained as follows:

$$
\begin{aligned}
& \sigma_{s}(t)=\frac{A E}{2 A_{s}}\left[\sigma_{I}(t)+\sigma_{R}(t)+\sigma_{T}(t)\right], \\
& \dot{\varepsilon}_{s}(t)=\frac{C}{\mathrm{El}}\left[\sigma_{T}(t)+\sigma_{R}(t)-\sigma_{I}(t)\right], \\
& \varepsilon_{s}(t)=\int_{0}^{t} \dot{\varepsilon}_{s}(t) d t,
\end{aligned}
$$

where $\sigma_{R}(t), \sigma_{I}(t)$, and $\sigma_{T}(t)$ denote the reflection stress, incident stress, and transmission stress, respectively. $\dot{\varepsilon}_{s}(t)$, $\sigma_{s}(t)$, and $\varepsilon_{s}(t)$ represent the strain rate, dynamic stress, and strain of the coal sample, respectively. $A$ and $A_{s}$ stand for the cross-sectional areas of the elastic bar and coal sample, respectively. $C$ and $E$ signify the P-wave velocity and elastic modulus of the elastic bar, respectively. $l$ symbolizes the length of the coal sample.

2.3. Experimental Procedures for Coal Samples. To study the characteristics of burst-prone coal under dynamic load disturbance in a high ground stress environment, the dynamic properties of coal with a different burst tendency were tested under the combined action of axial stress and cyclic impact loads. As shown in Figure 3(c), the coal sample was subjected to both the confining pressure $p$ ' and axial pressure $p_{c}$. To simulate the real stress state of deep coal mass, the confining stress of coal was set to be $5 \mathrm{MPa}$. The axial pressure $p_{c}$ included the preapplied static load $p_{a s}$ and the dynamic impact disturbance $p_{\mathrm{d}}$. Because the uniaxial compressive strength of the two coal samples was $18.16 \mathrm{MPa}$ and $10.78 \mathrm{MPa}$, respectively, the axial stress was set to be $2 \mathrm{MPa}, 5 \mathrm{MPa}$, and 


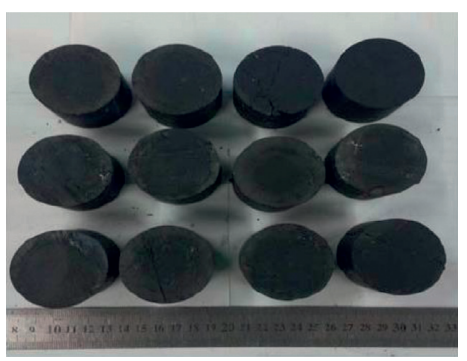

(a)

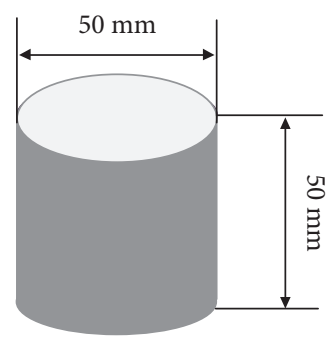

(b)

Figure 2: The experimental coal samples: (a) part of the prepared coal sample. (b) The geometric dimension of the coal sample.

TABLE 1: The mechanical and physical properties of coal under a quasistatic condition.

\begin{tabular}{|c|c|c|c|c|c|c|}
\hline Coal source & $\begin{array}{l}\text { Density } \\
\left(\mathrm{g} \cdot \mathrm{cm}^{-3}\right.\end{array}$ & $\begin{array}{l}\text { Uniaxial compressive } \\
\text { strength }(\mathrm{MPa})\end{array}$ & $\begin{array}{c}\text { Elastic modulus } \\
(\mathrm{GPa})\end{array}$ & $\begin{array}{l}\text { Poisson's } \\
\text { ratio }\end{array}$ & $\begin{array}{l}\text { Cohesion } \\
(\mathrm{MPa})\end{array}$ & $\begin{array}{c}\text { Friction angle } \\
\left({ }^{\circ}\right)\end{array}$ \\
\hline Qianqiu coal mine (prone) & 1.32 & 18.16 & 4.85 & 0.38 & 12.84 & 25.41 \\
\hline $\begin{array}{l}\text { Zhaogezhuang coal mine } \\
\text { (resistant) }\end{array}$ & 1.34 & 10.78 & 2.21 & 0.27 & 11.02 & 17.05 \\
\hline
\end{tabular}

$8 \mathrm{MPa}$, respectively. Each test was repeated for three coal samples. It was ensured that the axial preapplied stress and confining stress remained unchanged before each impact.

Before the impact test, a small amount of grease was applied to the contact part between the sample and the loading bar to prevent the interference of friction effect on the test results. Moreover, a brass plate was pasted on the incident bar's end as a waveform shaper to prolong the loading wave and to reduce the wave oscillation. This approach could achieve the ideal sinusoidal loading waveform. Before each impact, the air pressure in the gas gun was set to $0.5 \mathrm{MPa}$, and the position of the spindle punch in the emission cavity was ensured to be unchanged. The specimens were subjected to cyclic impact, and the value of preloaded axial pressure was adjusted after each impact until the failure of the coal sample was completed.

\section{Results and Discussion}

Before conducting experiments on the dynamic mechanical features of the coal samples, the mineral composition and organic component of the two coal samples (burst-prone and burst-resistant) were analyzed by XRD and optical microscope method. Thereafter, the relationships between the burst propensity of coal and the parameters of microcrystallinity, inertinite, vitrinite, exinite, and mineral composition were discussed and analyzed.

\subsection{X-Ray Diffraction Analysis of Burst-Prone Coal Specimens.} $\mathrm{X}$-ray diffraction is a key technique for determining crystal structures. It is also extensively utilized for analyzing the physical structure of amorphous substances. Many scholars have employed the XRD method to explore the structure of coal and have achieved considerable advancements [18]. The mineral types and contents of burst-prone and burst-resistant coals were analyzed by X-ray diffraction (Table 2). The experiment was conducted using the D/Max-2500 X-ray diffractometer (Rigaku company). The experimental results demonstrated that the content of amorphous and clay minerals in coal differs significantly under various geological formations. Even for coal samples from the same seam, there were slight differences in component content, but the overall distribution structure of mineral content was stable. The clay mineral content of burstprone coals was less compared to the burst-resistant coals.

Based on the theories of coal chemistry and coal petrology, the alterations in the mechanical and physical features of coal can also be investigated by the values of microcrystalline parameters in the coal. The distance $d_{002}$ between aromatic monolayers (002 surface mesh spacing), the average lamella stacking thickness $L_{\mathrm{C}}$ of microcrystalline layers, and the aromatic lamella diameter $L_{\mathrm{a}}$ are commonly used as microcrystalline parameters for coal as follows:

$$
\begin{aligned}
d_{002} & =\frac{\lambda}{2} \sin \theta_{002}, \\
L_{c} & =0.94 \frac{\lambda}{\beta_{002}} \times \cos \theta_{002}, \\
L_{a} & =1.84 \frac{\lambda}{\beta_{100}} \cos \theta_{100},
\end{aligned}
$$

where $\lambda$ is the wavelength of X-ray, $\theta_{002}$ and $\theta_{100}$ denote the peaks of (002) and (100), respectively, and $\beta_{002}$ and $\beta_{100}$, respectively, stand for the integral half-height width of the two peaks.

The results of the comparative analysis of the coal samples by XRD method are shown in Table 3. From the analysis of the data in the table, it was found that the $\Delta L=\left(L_{\mathrm{a}}-L_{\mathrm{c}}\right) L_{\mathrm{c}}$ or $L_{\mathrm{a}} L_{\mathrm{c}}$ value of Qianqiu coal was larger than that of Zhaogezhuang coal. Figure 4 exhibits the $\mathrm{X}$-ray diffraction patterns of the coal specimens with different burst propensities.

Besides, according to the coal chemistry theory, the higher the (002) diffraction peak, the smaller the $d_{002}$, and the larger the 


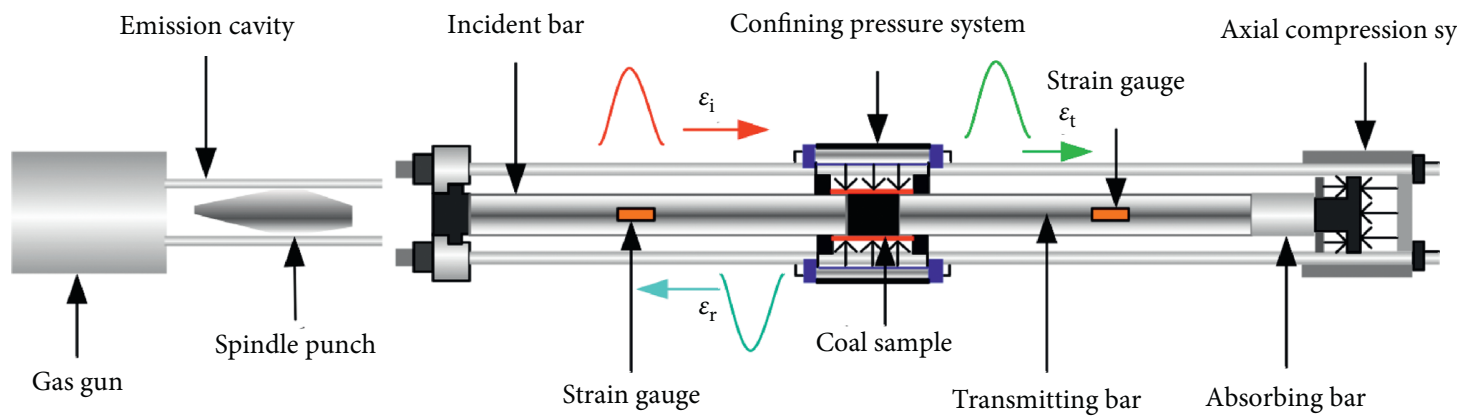

(a)
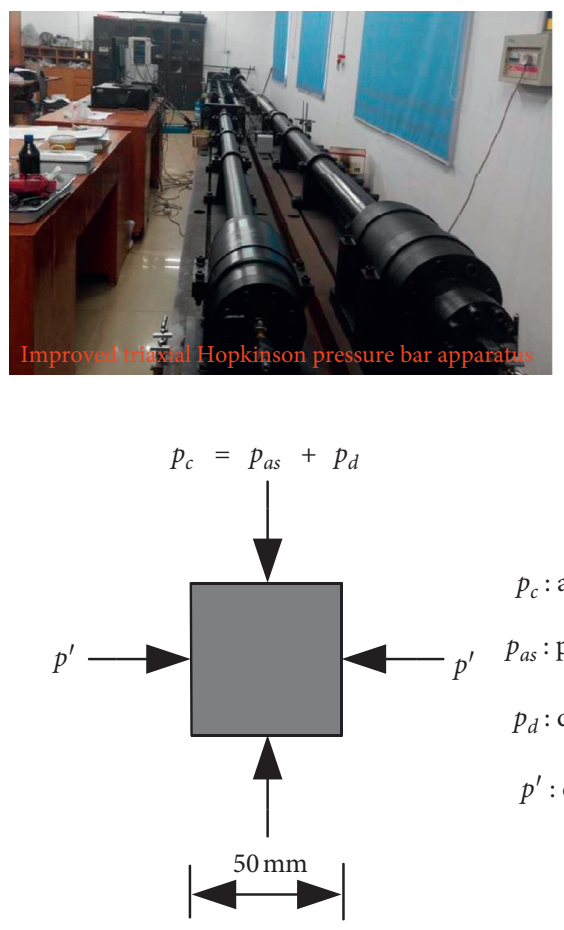

Loading diagram of coal sample
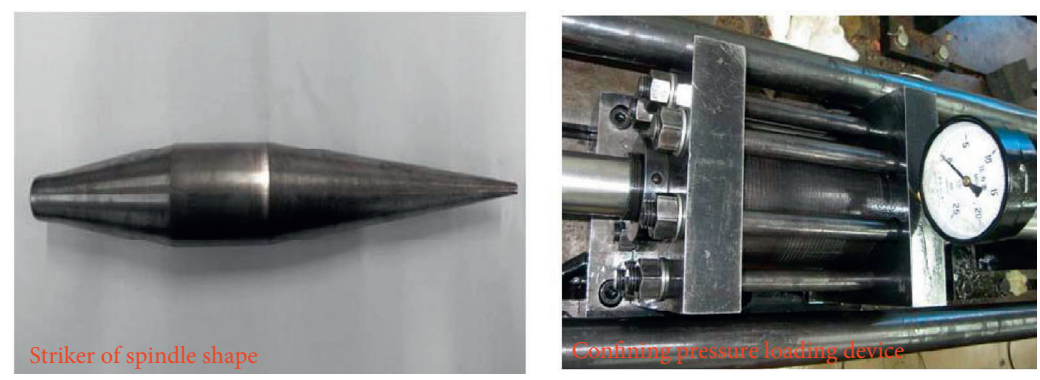

(b)

$$
p_{c} \text { : axial total applied load }
$$

$p_{a s}:$ preapplied static load

$p_{d}:$ dynamic load from shock

$p^{\prime}$ : confining pressure

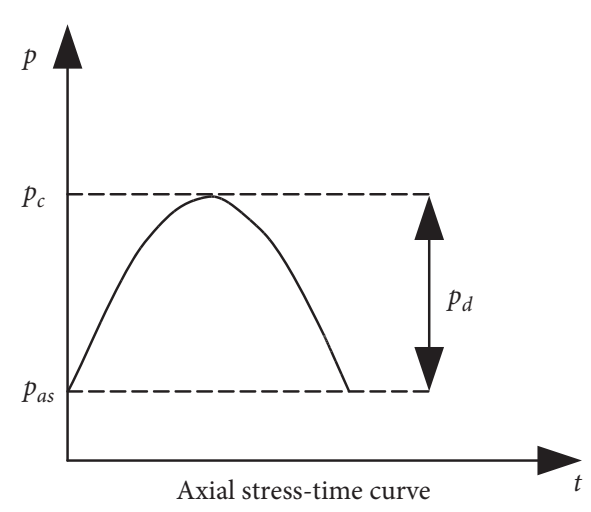

(c)

FIGURE 3: Experimental equipment and specimen loading mode: (a) schematic diagram of the improved Hopkinson pressure bar apparatus, (b) photographs of SHPB, and (c) schematic diagram of the composition of the load applied to the specimen.

$L_{\mathcal{c}}$, meaning the higher the degree of coal deterioration. It was concluded that the degree of deterioration of Qianqiu coal was higher than that of Zhaogezhuang coal. However, it could not be concluded that the higher the degree of deterioration, the stronger the burst tendency of the coal. The degree of deterioration directly affects the mechanical and physical features of the coal. This is primarily because the degree of deterioration is related to the physical properties such as hardness, brittleness, and porosity of the coal. The available scientific data suggest that until now, coal burst has occurred in all coal types except lignite. Lignite is the coal with the lowest degree of deterioration and microhardness.

\subsection{Relationship between Bust Tendency and Macerals of Coal.} The distribution, content, and vitrinite reflectance of macerals within coal with various burst propensities were observed using an Orthoplan MPV-3 microscope photometer (Leitz Co., Germany). A relationship was found between the microcomponent and the burst propensity of the coal. Also, the influence of different microcomponents on the burst propensity and structural characteristics of the coal was analyzed. The samples were the same as those in the XRD experiment, and the test results are displayed in $\mathrm{Ta}-$ bles 4 and 5 .

It could be concluded that the exinite and mineral composition of the coal had little influence on the burst propensity of the coal. Coal's burst propensity was strongly correlated with the content of organic matter in the vitrinite and inertinite groups of the coal. Burst-prone coals possessed more vitrinite and less inertinite. Compared with the burst-resistant coal samples, the burst-prone coals contained less corpocollinite and fusinite. It should be noted that there was a certain correlation between the content of clay mineral 
TABle 2: Analysis of coal specimens through the XRD method.

\begin{tabular}{|c|c|c|c|c|c|}
\hline \multicolumn{2}{|c|}{ Coal source } & \multicolumn{2}{|c|}{$\begin{array}{l}\text { No. } 2 \text { coal seam } \\
\text { of Qianqiu mine }\end{array}$} & \multicolumn{2}{|c|}{$\begin{array}{c}\text { No. } 7 \text { coal seam } \\
\text { of Zhaogezhuang mine }\end{array}$} \\
\hline \multirow{3}{*}{\multicolumn{2}{|c|}{$\begin{array}{l}\text { Serial number } \\
\text { Depth }(\mathrm{m}) \\
\text { Properties }\end{array}$}} & QQ-1 & QQ-2 & ZGZ-1 & ZGZ-2 \\
\hline & & -1060 & -1060 & -1100 & -1100 \\
\hline & & Burst-prone & Burst-prone & Burst-resistant & Burst-resistant \\
\hline \multirow{6}{*}{$\begin{array}{l}\text { Mineral type and } \\
\text { content }(\%)\end{array}$} & Quartz & 1.5 & 0.8 & & \\
\hline & Calcite & & & 1.1 & 1.2 \\
\hline & Dolomite & & 1.2 & & \\
\hline & Siderite & 1.6 & 1.1 & & \\
\hline & Halite & & & 0.9 & \\
\hline & Amorphous & 90.8 & 90.9 & 90.2 & 91.3 \\
\hline \multicolumn{2}{|c|}{ Clay mineral content (\%) } & 6.1 & 6.0 & 7.8 & 7.5 \\
\hline
\end{tabular}

Note: QQ represents Qianqiu mine and ZGZ signifies Zhaogezhuang mine.

TABLE 3: Comparison of the XRD structural parameters of the coal samples.

\begin{tabular}{lccccccccc}
\hline Coal source & $2 \theta_{002}\left({ }^{\circ}\right)$ & $\beta_{002} \mathrm{rad}$ & $2 \theta_{100}\left(^{\circ}\right)$ & $\beta_{100} \mathrm{rad}$ & $d_{002} \mathrm{~nm}$ & $L_{\mathrm{c}} \mathrm{nm}$ & $L_{\mathrm{a}} \mathrm{nm}$ & $L_{\mathrm{a}} L_{\mathrm{c}}$ & $\left(L_{\mathrm{a}}-L_{\mathrm{c}}\right) L_{\mathrm{c}}$ \\
\hline QQ & 23.9 & 0.172 & 42.7 & 0.305 & 0.373 & 0.857 & 0.996 & 1.952 & 0.952 \\
ZGZ & 22.7 & 0.266 & 43.2 & 0.258 & 0.405 & 0.692 & 1.129 & 1.165 & 0.165 \\
\hline
\end{tabular}

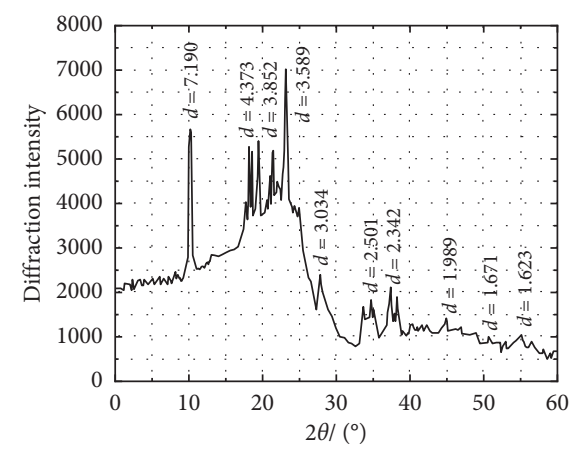

(a)

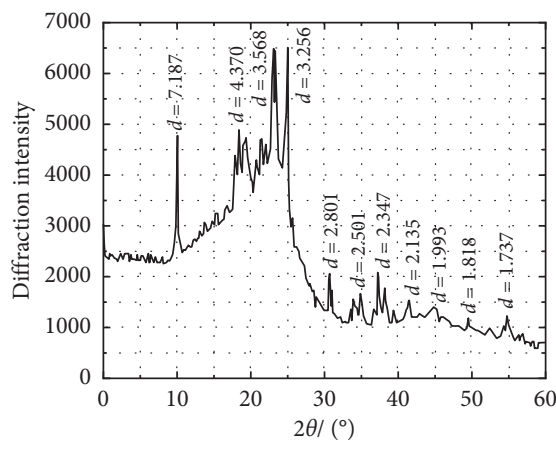

(b)

FIGURE 4: X-ray diffraction patterns of the coal specimens with different burst propensities: (a) Zhaogezhuang burst-resistant coal specimen; (b) Qianqiu burst-prone coal specimen.

and the burst propensity of coal (i.e., the greater content of clay mineral led to a less burst propensity). There is a consistency between this finding and the XRD analysis results. The content of organic components in coal has a significant effect on its physical and mechanical properties. This is determined chiefly by the mechanical features of the organic macerals, and various organic component contents have a great influence on the microhardness, microbrittleness, and toughness of coal. Based on current experimental information, it could be inferred that coals with greater microhardness and microbrittleness were more susceptible to burst.

In recent decades, with the advancement of optical microscopy technology and the application of advanced equipment, many scholars have utilized optical microscopy and other means to examine the level of coal metamorphism as well as the structural development of various coals under many high-pressure and high-temperature circumstances [18-20]. Among them, the vitrinite reflectance ratio in coal is a direct physical quantity representing the structural growth of the coal, and many studies have been conducted on this index. In this study, the burst propensity of the coal was not directly reflected by the vitrinite reflectance ratio. However, there was a definite correlation between the difference of the minimum and maximum reflectivity of the vitrinite and the burst propensity of the coal (i.e., the smaller difference resulted in the smaller burst propensity).

3.3. Dynamic Stress-Strain Relationship of Coal Specimens. To investigate the effect of various dynamic loading conditions on the dynamic properties of coal with different burst propensity, dynamic tests of the burst-prone and burstresistant coals were carried out under preaxial pressure and cyclic impact. At the end of the test, the data were compiled, the cumulative number of impacts for each sample was recorded, and the dynamic stress-strain curve was plotted. The cumulative number of impacts for each sample is 
TABLE 4: Quantitative statistical results of coal samples' macerals.

\begin{tabular}{lccc}
\hline & Coal macerals & Qianqiu coal & Zhaogezhuang coal \\
\hline \multirow{4}{*}{ Vitrinite } & Desmocollinite & 3.1 & 10.7 \\
& Telocollinite & 45.2 & 4.5 \\
& Telinite & 20.8 & 32.1 \\
& Corpocollinite & 2.5 & 7.2 \\
& Vitrodetrinite & & 0.2 \\
Inertinite & Semifusinite & 11.4 & 10.1 \\
& Fusinite & 9.1 & 9.3 \\
& Inert detritus & 4.5 & 16.4 \\
& Macrinite & & 0.2 \\
Exinite & Micronite & & 0.5 \\
& Sclerotinite & & 0.5 \\
\hline & Sporinite & & 0.4 \\
Minerals & Cutinite & & 7.4 \\
& Resinite & 0.4 & 0.5 \\
\hline
\end{tabular}

TABLE 5: Analysis results of vitrinite reflectance ratio in different coal samples.

\begin{tabular}{lccccc}
\hline Coal source & $R_{\min }(\%)$ & $R_{\max }(\%)$ & $R_{\mathrm{o}, \max }(\%)$ & $\left|R_{\max }-R_{\min }\right|(\%)$ & 0.18 \\
\hline Qianqiu coal & 1.18 & 1.23 & 1.21 & Measuring points \\
Zhaogezhuang coal & 1.10 & 1.20 & 1.15 & 0.08 & 20 \\
\hline
\end{tabular}

Note: $R_{\min }, R_{\max }$ and $R_{\mathrm{o} \text { max }}$ are, respectively, the minimum, maximum, and average reflectivity of vitrinite.

presented in Table 6. Also, the typical dynamic stress-strain curves for each set of tests are represented in Figure 5.

As the number of cyclic impact increased, the peak stress of each coal sample decreased and the peak strain increased, reflecting the damage and deterioration characteristics of the specimens under the cyclic impact. The deformation characteristics of the dynamic stress-strain curve before the peak stress were consistent with the results of Li et al.[16]. There was no compact phase, but only elastic and nonlinear deformation phases existed in the dynamic stress-strain curve. Comparing the dynamic stress-strain curves of different burst propensity coals, it was found that the peak stress of the burst-prone coals was larger compared to the burst-resistant coals, but the peak strain was less than that of the burst-resistant coals. Under the same axial stress, the maximum number of impacts that the burst-prone coal could withstand was significantly smaller than the burst-resistant coal, indicating that the burstprone coal had a weaker ability to resist cyclic shock disturbance.
3.4. Influence of Impact Times on Dynamic Peak Stress. Figure 6 displays the dynamic peak stresses in the coal samples at different axial pressures with the number of cyclic impacts. In general, the dynamic peak stress was diminished by an increase in the number of cyclic effects. A one-dimensional linear regression was performed on each set of data using the principle of least squares to derive the formula for each fit in the figure. By increasing the number of impacts, the coal samples exhibited dynamic fatigue characteristics.

Under constant axial pressure, when the number of cyclic impacts reached a certain value, the macroscopic damage occurred in the coal rock. The dynamic peak stress was also related to the preloaded axial pressure. Increasing the axial pressure within a certain range led to a decrease in the dynamic peak stress. This was because the preloaded axial pressures up to a certain value caused the microcracks within the coal sample to reexpand or caused new microcracks to be created, thereby reducing the ability of the coal rock to resist external shocks. The 
TABle 6: Statistical cumulative number of cyclic impacts.

\begin{tabular}{lccccc}
\hline \multicolumn{2}{c}{ Zhaogezhuang coal (resistant) } & \multicolumn{2}{c}{ Qianqiu coal (prone) } \\
Specimen number & Cumulative impact times & Axial stress (MPa) & Specimen number & Cumulative impact times & Axial stress (MPa) \\
\hline ZGZ1-1 & 10 & 8 & QQ1-1 & 5 & 8 \\
ZGZ1-2 & 12 & 8 & QQ1-2 & 4 & 8 \\
ZGZ1-3 & 15 & 8 & QQ1-3 & 6 & 8 \\
ZGZ2-1 & 20 & 5 & QQ2-1 & 8 & 5 \\
ZGZ2-2 & 17 & 5 & QQ2-2 & 9 & 5 \\
ZGZ2-3 & 19 & 5 & QQ2-3 & 11 & 2 \\
ZGZ3-1 & 23 & 2 & QQ3-2 & 13 & 2 \\
ZGZ3-2 & 21 & 2 & QQ3-3 & 14 & 2 \\
ZGZ3-3 & 26 & 2 &
\end{tabular}

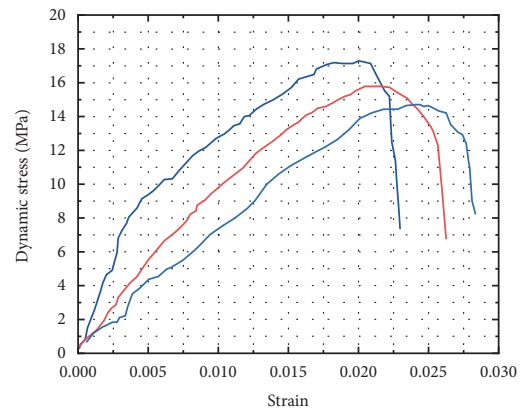

Impacting times

$N=1$

$N=6$

$-N=12$

(a)

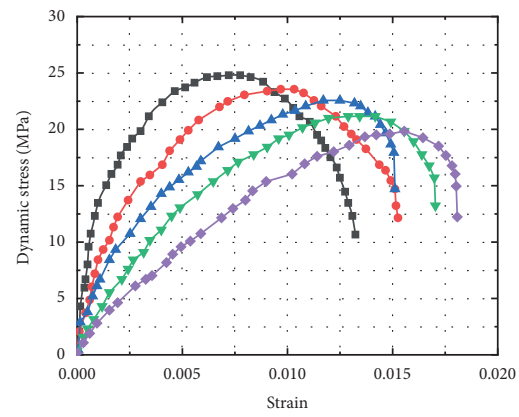

Impacting times

$\longrightarrow \quad N=1$

$\longrightarrow N=2$

$\longrightarrow N=$

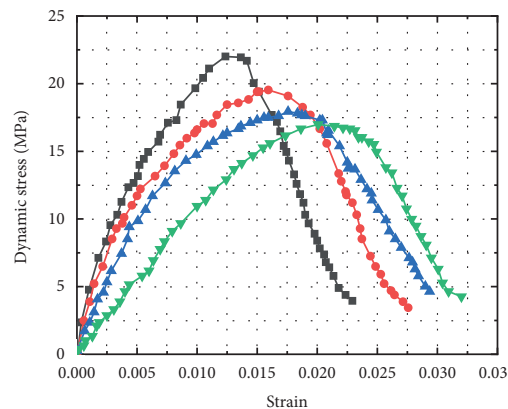

Impacting times

$\longrightarrow N=4$

$\longrightarrow N=9$

$\simeq \quad N=15$

(b)

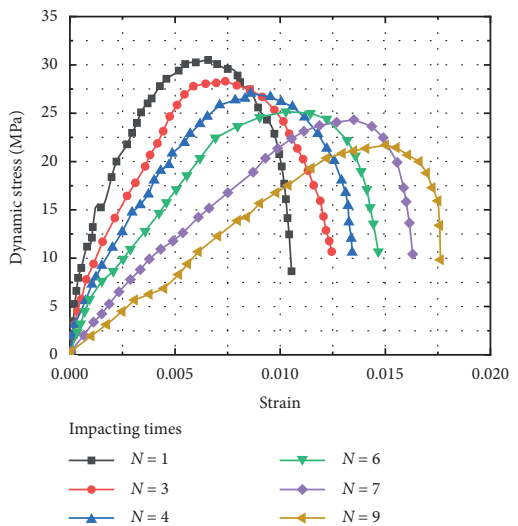

(e)

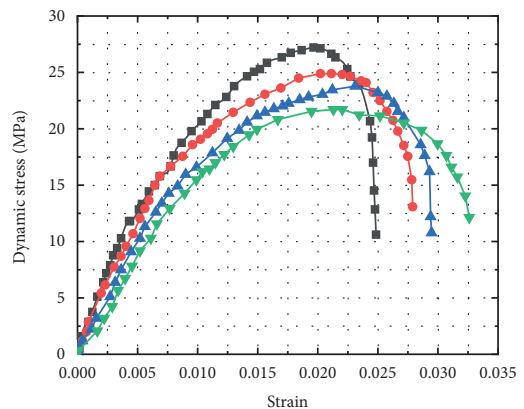

Impacting times

$\because N=4$
$-\quad N=12$

$\simeq N=19$

$\longrightarrow N=26$

(c)

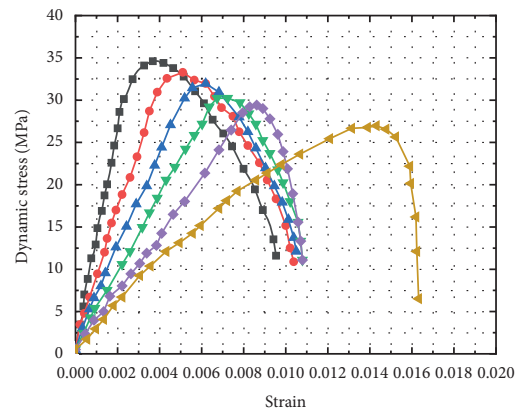

Impacting times

$\longrightarrow N=3$

$\longrightarrow N=6$

$\longrightarrow N=8$

$\longrightarrow N=10$

$\longrightarrow \quad N=12$

f)

FIgURE 5: The dynamic stress-strain curves of coal under different axial stresses and cyclic impacts: (a) axial stress is $8 \mathrm{MPa}$, no. XZY1-2; (b) axial stress is $5 \mathrm{MPa}$, no. XZY2-1; and (c) axial stress is $2 \mathrm{MPa}$, no. XZY3-3, for the Zhaogezhuang burst-resistant coal specimen; (d) axial stress is $8 \mathrm{MPa}$, no. YJ1-1; (e) axial stress is $5 \mathrm{MPa}$, no. YJ2-3; and (f) axial stress is $2 \mathrm{MPa}$, no. YJ2-3, for the Qianqiu burst-prone coal specimen. 


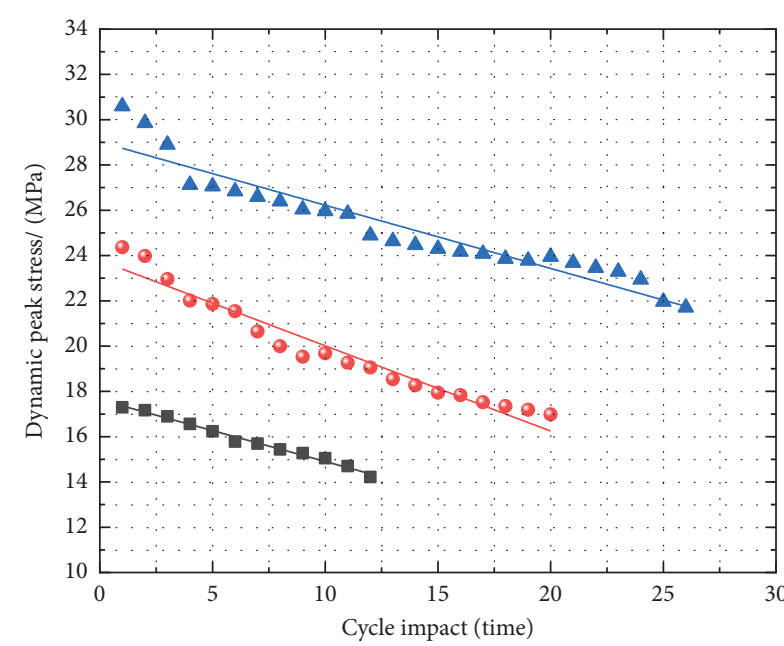

$$
\begin{aligned}
& \text { Axial prestress is } 8 \mathrm{MPa} \\
& \text { - Axial prestress is } 5 \mathrm{MPa}-y=17.6307-0.2727 x, R^{2}=0.989 \\
& \text { - Axial prestress is } 2 \mathrm{MPa} \\
& \text { - } y=23.7798-0.3766 x, R^{2}=0.9485 \\
& \hline y=29.0149-0.2792 x, R^{2}=0.9079
\end{aligned}
$$

(a)

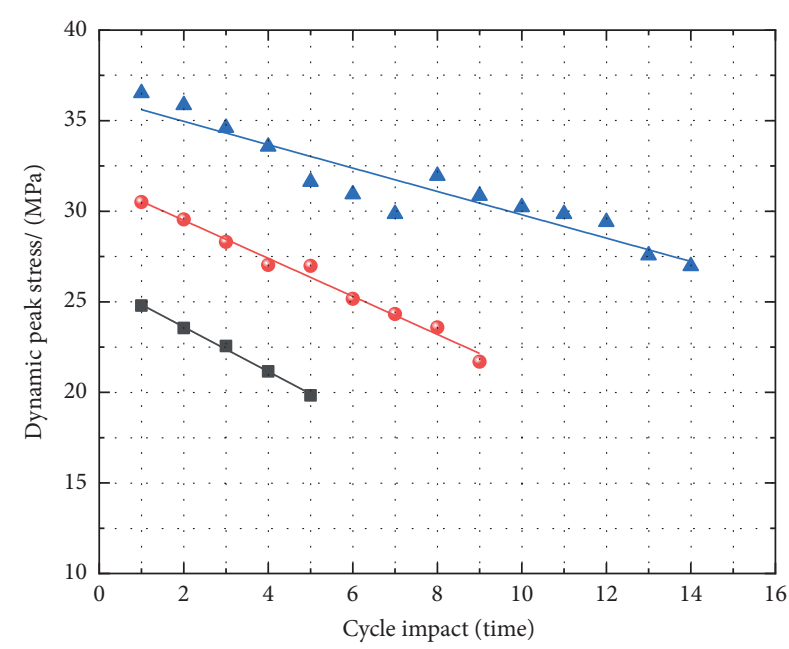

$$
\begin{aligned}
& \text { - Axial prestress is } 8 \mathrm{MPa} \\
& \text { - Axial prestress is } 5 \mathrm{MPa} \\
& \text { A Axial prestress is } 2 \mathrm{MPa} \\
& \begin{aligned}
y & =26.074-1.231 x, R^{2}=0.997 \\
y & =31.598-1.049, R^{2}=0.986 \\
& =36.252-0.645 x, R^{2}=0.888
\end{aligned}
\end{aligned}
$$

(b)

Figure 6: Relationship between dynamic peak stress and the number of impacts: (a) Zhaogezhuang burst-resistant coal specimens. (b) Qianqiu burst-prone coal specimens.

dynamic peak stress of coals with different burst propensities had the same trend with the number of cycle impacts. However, the peak stresses under different axial stresses of the Qianqiu coal were all larger than those of the Zhaogezhuang coal.

\section{Conclusion}

The objective of this work was to investigate the microstructure and macrodynamic mechanical features of burst-prone and burst-resistant coal comparatively. The mineral components, organic macerals, and dynamic mechanical features of both burst-prone and burst-resistant coal samples were comparatively analyzed based on the obtained X-ray diffraction (XRD), optical microscope observations, and dynamic compressive stress-strain curves, respectively. The following main conclusions were drawn from this study:

(1) The $\Delta L=\left(L_{\mathrm{a}}-L_{\mathrm{c}}\right) L_{\mathrm{c}}$ or $L_{\mathrm{a}} L_{\mathrm{c}}$ value of burst-prone coal was larger than that of the burst-resistant coal

(2) The organic matter in vitrinite and inertinite for coal had a significant influence on its burst propensity

(3) Compared to the burst-resistant coal samples, the burst-prone coal samples possessed less corpocollinite and fusinite

(4) The peak stress of burst-prone coals was larger compared to the burst-resistant coals, but the peak strain was less than that of burst-resistant coals

(5) Under the same axial stress, the maximum number of impacts that the burst-prone coal could withstand was substantially smaller than that of the burst-resistant coal

\section{Data Availability}

The data used to support the findings of this study are available from the corresponding author upon request.

\section{Conflicts of Interest}

The authors declare that they have no conflicts of interest.

\section{Acknowledgments}

This work was financially supported by the research fund of the National Natural Science Foundation of China (51604093), the Fundamental Research Funds for the Universities of Henan Province (Grant no. NSFRF200332), the Henan Key Laboratory for Green and Efficient Mining and Comprehensive Utilization of Mineral Resources (Henan Polytechnic University) (KCF201804), the Key Scientific Research Project Fund of Colleges and Universities of Henan Province (21A610005 and 20B440001), and the Doctoral Foundation of Henan Polytechnic University (B2019-22). All supports are greatly appreciated.

\section{References}

[1] L. Yuan and P. S. Zhang, "Development status and prospect of geological guarantee technology for precise coal mining," Journal of China Coal Society, vol. 44, no. 8, pp. 2277-2284, 2019.

[2] W. Cai, L. Dou, G. Si et al., "A new seismic-based strain energy methodology for coal burst forecasting in underground coal mines," International Journal of Rock Mechanics and Mining Sciences, vol. 123, Article ID 104086, 2019.

[3] A. Cao and M. Ataei, "Fuzzy fault tree analysis for coal burst occurrence probability in underground coal mining," 
Tunnelling and Underground Space Technology, vol. 83, pp. 165-174, 2019.

[4] D. Song, X. He, E. Wang, Z. Li, M. Wei, and H. Mu, "A dynamic ejection coal burst model for coalmine roadway collapse," International Journal of Mining Science and Technology, vol. 29, no. 4, pp. 557-564, 2019.

[5] I. Li and T. Stephen, "Occurrence, predication, and control of coal burst events in the U.S." International Journal of Mining Science and Technology, vol. 26, no. 1, pp. 39-46, 2016.

[6] X. Li and Y. Chai, "Determination of pillar width to improve mining safety in a deep burst-prone coal mine," Safety Science, vol. 113, pp. 244-256, 2019.

[7] W. J. Gale, "A review of energy associated with coal bursts," International Journal of Mining Science and Technology, vol. 28 , no. 5, pp. 755-761, 2018.

[8] C. Zhang, I. Canbulat, B. Hebblewhite, and C. R. Ward, "coal burst phenomena in mining and insights into directions for future research," International Journal of Coal Geology, vol. 179, pp. 28-44, 2017.

[9] C. Canbulat, "Coal bursts that occur during development: a rock mechanics enigma," International Journal of Mining Science and Technology, vol. 28, no. 1, pp. 35-42, 2018.

[10] L. Cai, S. B. Xie, Q. X. Huang et al., "The development of coal reservoir fracture and its geological controls in zhengzhuang block, southern qinshui basin, China," Advanced Materials Research, vol. 962-965, pp. 147-151, 2014.

[11] J. Zhu, H. Shi, Y. Shu et al., "Organic maceral characteristics and hydrocarbon-generating potentials of source rocks in the Pearl River Mouth basin," Petroleum Geology and Experiment, vol. 15, no. 1, pp. 17-35, 2007.

[12] L. Y. Li, Z. Q. Xu, H. P. Xie et al., "Failure experimental study on energy laws of rock under differential dynamic impact velocities," Journal of China Coal Society, vol. 36, no. 12, pp. 2007-2011, 2011.

[13] S. Gong, Z. Wang, G. Q. Zhang et al., "Influence of water content and maceral composition on the properties of outburst-prone coal: laboratory experiment," IOP Conference Series: Earth and Environmental Science, vol. 570, Article ID 032038, 2020.

[14] F. N. Jin, M. R. Jiang, X. L. Gao et al., "Defining damage variable based on energy dissipation," Chinese Journal of Rock Mechanics and Engineering, vol. 23, no. 12, pp. 1976-1980, 2004.

[15] J. Liu, J. L. Li, Y. D. Zhang et al., "Analysis of energy characteristics and deformation parameters of rock mass under cyclic loading," Chinese Journal of Rock Mechanics and Engineering, vol. 29, no. S1, pp. 3505-3513, 2010.

[16] X. B. Li, T. S. Lok, J. Zhao, and P. J. Zhao, "Oscillation elimination in the hopkinson bar apparatus and resultant complete dynamic stress-strain curves for rocks," International Journal of Rock Mechanics and Mining Sciences, vol. 37, no. 7, pp. 1055-1060, 2000.

[17] X. B. Zhao, Y. J. Zuo, C. D. Ma et al., "Constitutive model of rock under coupled static-dynamic loading with intermediate strain rate," Chinese Journal of Rock Mechanics and Engineering, vol. 25, no. 5, pp. 865-874, 2006.

[18] J. Karas, R. J. Pugmire, W. R. Woolfenden, D. M. Grant, and S. Blair, "Comparison of physical and chemical properties of maceral groups separated by density dradient centrifugation," International Journal of Coal Geology, vol. 5, no. 4, pp. 315338, 1985.

[19] S. Gong, Study on Mechanical Characteristics of Dynamic Tensile and Mode I Fracture of Coal Samples under Impact
Loading, China University of Mining and Technology, Beijing, China, 2018.

[20] J. Shepherd, L. K. Rixqn, and L. Griffiths, "Out bursts and geological structures in coal mines," International Journal of Rock Mechanics and Mining Sciences, vol. 18, no. 1, pp. 267-283, 1981. 